\title{
Exposure to phosphine in maritime transport: a real and important occupational risk: a report of three cases
}

\author{
David Lucas $^{1}$, Gilles Mauguen ${ }^{2}$, Philippe Lesné ${ }^{3}$, Elsa Polard ${ }^{4}$, Dominique Jegaden ${ }^{1}$ \\ ${ }^{1}$ French Maritime Medicine Society, France \\ ${ }^{2}$ Regional Agency of Health Insurance And Retirement of Brittany, Rennes, France \\ ${ }^{3}$ Regional Agency of Health Insurance And Retirement of Normandy, Rouen, France \\ ${ }^{4}$ Regional Direction of Labour Inspection of Brittany, Brest, France
}

\begin{abstract}
In maritime transport, to assess the risks of insect pests spreading, fumigation is recommended by the Food and Agriculture Organisation. Fumigant mostly used for foodstuffs is the phosphine gas generated by the reaction of aluminium phosphide and moisture in the atmosphere. In this article, we first discuss phosphine toxicity to humans and then we describe three cases of occupational exposure in maritime transport of cereals. We found phosphine level higher than 20 ppm in tank atmosphere of bulk carriers and levels from 2 to $3.5 \mathrm{ppm}$ in port silos and port warehouses where cereals were unloaded. Two weeks later, atmospheric measurements in a silo were still at $0.8 \mathrm{ppm}$. In this case, 3 workers described symptoms which could be linked with phosphine. Exposures to phosphine and cases in maritime transport are surely underestimated. Exposure could occur at sea, in harbour but also in port warehouses, trucks and silos or warehouses along logistic chain. All workers in the chain could be exposed. We can recommend research aiming at the development of alternative techniques using a less harmful gas for humans. At individual level, we propose that, along with the training for employees, workers potentially exposed should wear a test strip (phosphine detector strips) or a personal gas badge with appropriate maintenance.
\end{abstract}

(Int Marit Health 2018; 69, 3: 181-183)

Key words: phosphine intoxication, maritime toxicology, fumigants, maritime transport

\section{INTRODUCTION}

Shipping has grown exponentially in the last 20 years. According to the United Nations Conference on Trade and Development, in 2015, world maritime trade reached the level of 9.86 billion tons transported [1].

The major growth was for container $(5.6 \%)$ and bulk carrier (5\%). In 2012, 1.5 billion tons of goods and 450 million tons of grain were transported by container [2]. High level of intercontinental travel (mainly Southeast Asia-Europe-America) treating goods by insecticides is recommended by the Food and Agriculture Organism (FAO). The most common process is fumigation, especially by phosphine for stored products. Methyl bromide and sul- phide fluoride are commonly used for pallets, dunnage (ISPM 15) and wood logs.

Tablets or socks of aluminium or magnesium phosphorus are used. Metal phosphide is hydrolysed in contact with moisture in the air and in goods and gaseous phosphine (PH3) was released in container or in tank.

\section{CASE REPORTS}

We described three cases of this occupational risk in maritime transport.

For phosphine measurements, the chemical expert who carried out analysis in the cases described, used a RAE system device, equipped with $\mathrm{O} 2, \mathrm{PH} 3, \mathrm{CO}, \mathrm{H} 2 \mathrm{~S}$ detector. 
Table 1. Exposure assessment in tank atmosphere - case 2

\begin{tabular}{|c|c|c|c|}
\hline & & $\begin{array}{l}\text { PH3 [ppm] } \\
\text { OEL = } 0.1 \text { ppm }\end{array}$ & $\begin{array}{l}\text { CO [\%] } \\
\text { OEL = } 50 \text { ppm }\end{array}$ \\
\hline \multirow{6}{*}{$\begin{array}{l}21 / 01 / 2016 \\
5 \text { h } 10 \mathrm{~min}\end{array}$} & Tank 1 & 2.8 & 9 \\
\hline & Tank 2 & 20 & 163 \\
\hline & Tank 3 & 1.1 & 0 \\
\hline & Tank 4 & 11.6 & 27 \\
\hline & Tank 5 & 20 & 248 \\
\hline & Deck & 0.3 & 0 \\
\hline \multirow{6}{*}{$\begin{array}{l}21 / 01 / 2016 \\
8 \text { h } 10 \mathrm{~min}\end{array}$} & Tank 1 & 1.6 & 4 \\
\hline & Tank 2 & 20 & 500 \\
\hline & Tank 3 & 1 & 0 \\
\hline & Tank 4 & 11.6 & 28 \\
\hline & Tank 5 & 20 & 250 \\
\hline & Deck & 0.1 & 0 \\
\hline \multirow[t]{5}{*}{$27 / 01 / 2016$} & Tank 1 & 0.2 & 0 \\
\hline & Tank 2 & 0.2 & 0 \\
\hline & Tank 3 & 0.2 & 0 \\
\hline & Tank 4 & 0.2 & 0 \\
\hline & Tank 5 & 0.2 & 0 \\
\hline
\end{tabular}

\section{FIRST CASE}

In 2013, during maize unloading in a French harbour, atmospheric measurements were carried out on workers (dockers, silo port workers) and inside several tanks. The sampling time was from 120 to 160 minutes. All results of measurements on workers were negative. Also, only one fixed support in a manhole returned positive at $0.3 \mathrm{ppm}$.

\section{SECOND CASE}

In January 2016, a vessel carrying soya came to Brest harbour for unloading. Due to Brest port authorities' protocol, atmospheric samples of the holds with oxygen, carbon monoxide and phosphine levels were done before allowing unloading. Results of tanks' atmosphere levels are shown in Table 1.

\section{THIRD CASE}

Romanian ship carrying maize came to Brest mid-December 2016. The most interesting gas concentrations are reported in Tables 2 and 3.

When the ship arrived to the harbour, the atmospheric samples showed high levels of phosphine in two holds, one had been discharged in part in Spain. Tanks unloaded in Spain were gas-free.

Fumigation process used by those three vessels follow one of the FAO recommendations.
1. Putting phosphine formulations in the grain mass with or without overlap using plastic sheeting.

2. Performing fumigation on the surface of the grain: the fumigation of bulk grains should be done at temperatures above $15^{\circ} \mathrm{C}$ and with adequate doses applied.

3. Spot fumigation, in which only limited portions of the grain are fumigated by survey formulations in areas identified as infested, is not recommended

High capacity of grain can also be processed in ship holds with aboard fumigation procedure so-called "in transit" vessel. Redlinger et al. (1979) [3] found that adequate gas dispersion and control of insects were obtained when aluminium phosphide tablets were spread on the grain at intervals during the loading operation. This process is normally only for silos with automatic tablet dispensers, but it seems to be used on board in some countries.

Ships' fumigation should never be carried out during loading. Nevertheless, hydrolysis of aluminium phosphide starts after 3 hours and in case of rain or overnight loading, holds are regularly closed. It could result in high concentrations of phosphine trapped in tanks when re-opening holds [4-6].

\section{CONCLUSIONS}

We highlight the complexity and hardness of prevention of this cereal fumigation technique by aluminium phosphide or magnesium. At the global level, maritime 
Table 2. Exposure assessment in tank atmosphere - case 3

\begin{tabular}{lll}
\hline Date and hour & Tank $\mathbf{3}$ & Tank $\mathbf{6}$ \\
\hline 16/12/2016 -6 h 0 min & $>20$ & $>20$ \\
16/12/2016 -9 h 45 min & 0.3 near tank & 0.2 near tank \\
(after tank ventilation) & 8.1 at the door & $>20$ at the door \\
Vend 16/12/2016 & 2.1 & $>20$ \\
- 16 h 0 min & \\
Sam 17/12/2016 & Illegible & $>20$ \\
-6 h 20 min & & \\
19/12/2016 - 5 h 50 min & 0.1 & 0.1
\end{tabular}

Table 3. Exposure assessment in port facilities - case 3

\begin{tabular}{llll}
\hline Date and hour & Warehouse & Silo & Crane \\
\hline $17 / 12 / 2016-6 \mathrm{~h}$ & 3.5 & & 0 \\
$17 / 12 / 2016-9 \mathrm{~h}$ & 2.5 & & \\
$19 / 12 / 2016$ & 0.6 & 0.6 & \\
$20 / 12 / 2016$ & 0.4 & 1.3 & \\
$21 / 12 / 2016$ & 0 & 0.7 & \\
$31 / 12 / 2016$ & & 0.8 & \\
$02 / 01 / 2017$ & & 0.2 &
\end{tabular}

fumigation is governed by the IMDG code published by the International Maritime Organisation. In France, the fumigation of stored products is supervised by the Ministry of Agriculture; employees are trained and certified by an approved school. Certification standards vary widely between countries.

Accidents aboard ships are often the result of error or non-compliance with detecting procedures during travel.
We can wonder if the information and the training given to the crew are sufficient?

As for the logistics chain, most accidents occur due to lack of knowledge of the risk. One of the main problems is that fumigation and degassing are not always carried out by the same company. The goods are often sold free on board fumigated that is to say that legal responsibility for the fumigation goes from the seller to the buyer with sometimes a lack of knowledge of the risks and precautions to take when the goods arrive.

One of the prevention axes that arise is organisational with transfer of fumigation technical data, processes to be respected by all the actors of the chain of transport. Port stakeholders, including captaincy, have a role to play in these procedures. The example of setting up a certificate of declaration of fumigated goods with specific data as developed in Brittany seems very interesting to us.

Fumigation with phosphides is recommended by FAO because it is technically simple and cheap. Its relevance in preventing the spread of insects is not to be questioned. Its use has increased since the Montreal protocol banned methyl bromide. We can only recommend the research for alternative techniques using a less harmful gas for humans. At the individual level, we propose that, along with the training for employees, workers potentially exposed should wear a test strip (phosphine detector strips) or a personal badge gas with appropriate maintenance and training.

\section{REFERENCES}

1. http://ww2.ac-poitiers.fr/ecogest/spip.php?article901.

2. http://www.crsl.com/acatalog/shipping-review-and-outlook.html.

3. Redlinger LM, Zettler JL, Leesch JG, et al. In-transit shipboard fumigation of wheat J Econ Entomol. 1979, 72(4): 642-647.

4. http://www.fao.org/docrep/x5042e/x5042e0n.htm.

5. http://www.fao.org/docrep/x5048e/x5048E0o.htm.

6. http://www.atsdr.cdc.gov/MHMI/mmg177.pdf. 